\title{
UMA EXPERIÊNCIA DE ENSINO DE FÍSICA CONTEXTUALIZADA PARA A EDUCAÇ̃̃O DE JOVENS E ADULTOS
}

\author{
Wilson Leandro Krummenauer* \\ Sayonara Salvador Cabral da Costa** \\ Fernando Lang da Silveira***
}

RESUMO: Neste artigo, apresenta-se um exemplo de como é possível ensinar conteúdos de Física, significativamente, para estudantes de Ensino Médio vinculados à Educação de Jovens e Adultos (EJA), baseando-nos nas teorias de Paulo Freire, David Ausubel e Joseph Novak. O trabalho foi desenvolvido a partir de uma inquietação quanto aos resultados obtidos com estudantes de uma escola privada de um município do Rio Grande do Sul. Um levantamento prévio entre alguns professores da região mostrou que a maioria não diferenciava o tratamento em sala de aula praticado com estudantes em idade regular de escolarização e os alunos da EJA. Resgatando a legislação sobre a EJA e os Parâmetros Curriculares Nacionais (PCN) para o Ensino Médio, propusemo-nos a trabalhar com os alunos a partir das características profissionais comuns à maioria dos estudantes daquela localidade, resultando na escolha de um tema gerador relacionado ao processo de produção do couro. O desenvolvimento desse projeto e seus resultados constituíram a base de uma dissertação de mestrado, cujas características são apresentadas aqui, com a intenção de contribuir para a atividade de outros professores, tanto na modalidade da EJA como na de cursos regulares.

Palavras-chave: Movimento Circular Uniforme; Educação de Jovens e Adultos; Aprendizagem Significativa.

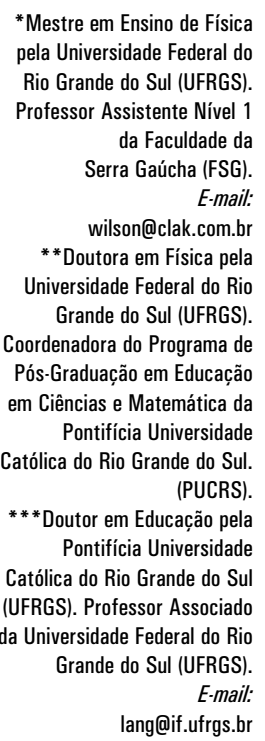

* Mestre em Ensino de Física pela Universidade Federal do Assistente Nivel da Faculdade da E-mail:

wilson@clak.com.br

* *Doutora em Física pela niversidade Federal do Rio Grande do Sul (UFRGS) Coordenadora do Programa de Pós-Graduação em Educação em Ciências e Matemática da Pontifícia Universidade Católica do Rio Grande do Sul. (PUCRS)

Pontifícia Universidade
Católica do Rio Grande do Sul
(UFRGS). Professor Associado
da Universidade Federal do Rio
Grande do Sul (UFRGS).
E-mail:
lang@if.ufrgs.br

\section{A CONTEXTUALIZED PHYSICS TEACHING EXPERIENCE FOR YOUTH AND ADULT LEARNING}

ABSTRACT: This article presents an example of how we can, meaningfully, teach Physics for high school students of Youth and Adult Learning courses, on the grounds of the theories of Paulo Freire, David Ausubel and Joseph Novak. The work was developed due to a concern about the results obtained from a private school in a town of Rio Grande do Sul. A preliminary survey, carried out with teachers in the region, showed that most of them did not adopt different approaches to students of regular school and those of youth and adult classes. Based on the legislation for youth and adult learning, as well as on the National Curriculum Parameters for high school, we developed our research taking into account professional characteristics common to most students in the region, which resulted in the choice of a theme related to the production process of leather. The development of this project and its results formed the basis for a master's thesis and its results were sufficiently promising to contribute to the activity of other teachers, both regarding youth and adult learning and regular courses.

Keywords: Uniform Circular Motion; Youth and Adult Learning; Meaningful Learning. 


\section{Introdução}

Os Parâmetros Curriculares Nacionais para o Ensino Médio (PCNEM) estabelecem que o ensino de Física deve ser desenvolvido adequando-o à realidade da escola. Também está claro nos PCNEM a intenção de se dar significado aos conteúdos de Física, relacionado-os ao cotidiano do aluno. Não se trata, portanto, de elaborar novas listas de tópicos de conteúdo, mas, sobretudo de dar ao ensino de Física novas dimensões, promovendo um conhecimento contextualizado e integrado à vida de cada jovem (BRASIL, 1999, p. 230).

Segundo o parecer 11 do Conselho de Educação Básica - CEB (apud SOARES, 2002), documento que regulamenta as Diretrizes Curriculares Nacionais para a Educação de Jovens e Adultos (EJA) aprovado em 10/05/2000, a EJA deve ter função reparadora, equalizadora e qualificadora. Reparadora, no sentido de reparar e restaurar o direito à educação que todo cidadão tem, independente da idade ou da condição social; reparado esse direito, chega-se a função equalizadora que visa uma redistribuição de igualdade de oportunidades, pois o processo deverá propiciar novas inserções no mercado de trabalho. Finalmente, a função qualificadora visa capacitar o aluno, por seu retorno à escola, aumentando suas oportunidades no mercado de trabalho e auxiliando na sua auto-estima.

O ensino de Física na Educação de Jovens e Adultos (EJA) requer estratégias diferenciadas das utilizadas no ensino regular, pois além das características peculiares dos estudantes dessa modalidade, o período de tempo disponível é muito reduzido, havendo também a necessidade de revisar conhecimentos básicos do ensino fundamental. A convivência do primeiro autor desse trabalho com alguns grupos da EJA de anos anteriores permitiu a constatação de que, em geral, os alunos desta modalidade não têm por objetivo fazer estudos posteriores em nível universitário e aquilo que eles aprenderem nesta etapa deverá lhes ser útil por toda a vida (KRUMMENAUER, 2009).

Percebemos, ao longo de cerca de 10 anos de trabalho com a EJA, que os índices de evasão de cursos desta modalidade são altíssimos. Entre as causas, destacam-se obstáculos de natureza cognitiva: em virtude de longos períodos longe dos bancos escolares, os alunos acabam por apresentar inúmeras lacunas de conhecimentos e dificuldades de compreensão de muitos conteúdos programáticos, sobretudo em Física no Ensino Médio.

Propostas desarticuladas com o contexto do cotidiano desses alunos e com as peculiaridades inerentes à modalidade EJA, aumentam essas dificuldades de aprendizagem, contribuindo para a repetência ou evasão. Assim sendo, consistentemente com o que propõe Freire (2001), entendemos que se faz necessário ensinar Física na EJA por meio de uma metodologia que parta do cotidiano do aluno trabalhador e que considere, sobretudo, suas vivências pessoais e profissionais.

Entrevistas feitas com alguns docentes da Região do Vale do Rio dos Sinos, RS, onde o trabalho, aqui relatado, aconteceu revelaram que os docentes 
não diferenciavam a metodologia utilizada para o Ensino Médio regular e para as turmas da EJA; a maioria deles não atribuiu diferença entre o estudante regular e o da EJA - as atividades, as avaliações e as aulas, são exatamente as mesmas.

Tais resultados configuraram um desafio, motivando-nos a desenvolver o trabalho que relatamos a seguir. Apresentamos uma proposta metodológica que foi construída tendo como fundamentação as teorias de aprendizagem de Ausubel e Novak e as ideias de Paulo Freire sobre a educação. Essa proposta foi aplicada a uma turma de 40 alunos do Ensino Médio da modalidade EJA, no ano de 2008, em uma escola privada, situada na região metropolitana de Porto Alegre, RS. Os alunos desta modalidade caracterizam-se por serem alunos trabalhadores do setor coureiro e calçadista na cidade. A escolha pelo tema Cinemática e Dinâmica do Movimento Circular Uniforme aconteceu a partir dos conhecimentos prévios do grupo de alunos relativos ao seu contexto profissional, tendo como intuito propiciar maior eficiência no processo de ensino e de aprendizagem.

$\mathrm{Na}$ literatura, encontramos outros trabalhos que também abordam a Física de maneira contextualizada na Educação Básica, como na dissertação de mestrado de Espíndola (2006), na qual é descrita uma metodologia para a EJA por meio de projetos didáticos. Assim como o presente trabalho, Espíndola utiliza, como referencial teórico, a aprendizagem significativa de Ausubel. Enquanto optamos pela escolha de um tema gerador, por razões já mencionadas, a autora desenvolveu um projeto no qual os alunos dividiram-se em pequenos grupos, cada um dos quais envolvidos com um tema gerador específico.

Gneiding e Garcia (2007), por sua vez, analisam resultados de uma pesquisa que visou identificar se trabalhadores de uma indústria de motores elétricos reconheciam a aplicação de conteúdos de Física em suas atividades profissionais. A pesquisa foi feita por meio de questionários aplicados aos alunos-trabalhadores, nos quais foi constatado que as respostas mais significativas foram dos alunos que frequentaram Cursos Técnicos e dos alunos que haviam concluído o Ensino Médio há menos tempo. Este trabalho reforça nossa intenção de apresentar a Física de forma contextualizada, aproveitando, sobretudo, experiências profissionais dos educandos, buscando identificar a presença dos conteúdos de Física em situações presenciadas no contexto profissional do aluno.

\section{Fundamentação Teórica}

Paulo Freire, David Ausubel e Joseph Novak apresentam concepções que são concordantes com o objetivo da proposta aqui apresentada:

- a estrutura cognitiva preexistente (AUSUBEL et al., 1980) é importante e fundamental no processo ensino-aprendizagem;

- o conteúdo de Física deve ser significante e relevante para o educando (op. cit. p. 89); 
- o professor também é um aprendiz: "não há docência sem discência" (FREIRE, 2001).

Do ponto de vista pedagógico, a proposta foi fundamentada nas ideias de Paulo Freire, conhecido mundialmente pelo seu método na alfabetização de adultos, razão pela qual se constitui em uma referência imprescindível para a Educação de Jovens e Adultos. Do ponto de vista psicológico, baseamo-nos na teoria de aprendizagem de David Ausubel e seu colaborador, Joseph Novak, para uma aprendizagem significativa, a partir da conscientização da necessidade de investigar a existência de possíveis "subsunçores" existentes na estrutura cognitiva dos educandos. Um "subsunçor" é um conceito ou uma ideia já existente na estrutura cognitiva do aluno, conceito esse que servirá de "ancoradouro" (MOREIRA; OSTERMANN, 1999) para a nova informação, adquirindo, desta maneira, significado para o aluno. A aprendizagem significativa, preconizada por Ausubel, ocorre quando "a nova informação adquire significado por interação com conceitos ou proposiçôes relevantes preexistentes na estrutura cognitiva” (op. cit. p. 62), sendo que esta relação deve ocorrer de maneira não-literal e não-arbitrária.

A aprendizagem significativa contrasta, fundamentalmente, com a aprendizagem mecânica, na medida em que, na primeira, a nova informação interage com algum "subsunçor", enquanto que na segunda, não há nenhuma interação entre a nova informação e os conceitos ou proposições preexistentes na estrutura cognitiva do aluno. Uma das causas é a própria inexistência de subsunçores. Um exemplo de aprendizagem mecânica é a memorização de um conteúdo sem qualquer fundamentação que lhe dê significado.

Segundo Ausubel e colaboradores, existem algumas condições essenciais para a ocorrência da aprendizagem significativa: i) o professor deve averiguar os conhecimentos prévios dos alunos e ensinar a partir destes conhecimentos; ii) outra condição fundamental para a ocorrência da aprendizagem significativa é que $o$ material utilizado seja potencialmente significativo, isto é, esteja relacionado com a estrutura cognitiva do aluno de maneira não-literal e não-arbitrária; iii) independente de o material ser potencialmente significativo ou não, para ocorrer a aprendizagem significativa o aprendiz deve ter predisposição em aprender de forma significativa - o aluno não pode ter a intenção de memorizar ou decorar o material, tal postura levará à aprendizagem mecânica, isto é, sem nenhuma relação entre a nova informação e a estrutura cognitiva do aprendiz.

A principal contribuição de Novak à teoria de aprendizagem significativa são os mapas conceituais, que são diagramas de relação hierárquica entre conceitos que refletem a estrutura de conceitos de certo conhecimento. Construir tais diagramas e refazê-los após análise e discussão são processos que facilitam a aprendizagem significativa. Os mapas conceituais também podem ser utilizados como instrumentos de avaliação, pois, pelos mesmos é possível analisar e perceber a ligação que o aluno faz entre conceitos, dando uma noção de como está organizada a estrutura cognitiva do aluno sobre um determinado assunto. 
Novak entende que o aprendiz cresce quando a aprendizagem é significativa, isto é, ocorre a motivação para novas aprendizagens, o que jamais ocorreria se a aprendizagem fosse mecânica (MOREIRA, 1999). Este fato é fundamental, pois como já comentamos anteriormente, uma das condições para a ocorrência da aprendizagem significativa é a predisposição em aprender.

A reflexão sobre a relação entre os fundamentos teóricos do professor-investigador e a prática no processo ensino-aprendizagem, amplamente discutida em mestrados profissionais da área de ensino de Ciências, tem ajudado a clarificar algumas concepções que os professores desenvolvem ao longo da sua prática docente. Nesse sentido, Valadares (2005) questiona os principais motivos para o insucesso do ensino de Física, sobretudo a repetência, e aponta soluções didáticas construtivistas para reverter tal quadro. Buscando o sucesso do processo ensino-aprendizagem, esse autor vê como alternativa a aprendizagem significativa de Ausubel, fundamental para o ensino de Física e para o rigor científico por parte do professor e dos materiais didáticos desenvolvidos. Por outro lado, Silva (2005) faz uma reflexão sobre a educação problematizadora de Freire para a prática docente nas escolas: "Entre educador e educandos não há mais uma relação de verticalidade, em que um é o sujeito e o outro objeto. Agora a pedagogia é dialógica, pois ambos são sujeitos do ato cognoscente" (op. cit., p. 3).

Os dois trabalhos mencionados vêm ao encontro da proposta aqui apresentada, pois, desenvolveu-se uma situação de ensino na qual o aluno atuou como sujeito da ação educativa e não apenas como o mero objeto receptor de informação.

Quanto à metodologia para o trabalho na EJA, Lozada e colaboradores (2008) sugerem o uso de textos na abordagem de conteúdos de Física em turmas da EJA do Ensino Médio, invocando as dificuldades inerentes a essa modalidade de ensino. A proposta foi aplicada em duas turmas da EJA em um trabalho interdisciplinar com a Matemática. Ainda assim, os resultados apontam dificuldades dos alunos quanto à compreensão de fenômenos físicos, bem como dificuldades em operações matemáticas. Nesse sentido, em nosso trabalho, também utilizamos textos com os alunos, construídos especialmente para o grupo, contextualizando o assunto para torná-lo um material didático potencialmente significativo.

\section{A Pesquisa}

Decidimos desenvolver uma proposta diferenciada para a turma de 2008 na escola onde trabalhamos. Nossa experiência anterior nesta escola revelou dificuldades para adequarmos o conteúdo previsto para o Ensino Médio aos alunos do EJA. Esperávamos combater também os altos índices de repetência e evasão registrados em anos anteriores. 


\subsection{Metodologia e caracterização do grupo}

A heterogeneidade do grupo de alunos com o qual desenvolvemos a proposta, característica comum das turmas da EJA, aumentou o desafio. Boa parte desses alunos havia abandonado o ensino regular há pouco tempo, mas alguns estavam retornando aos estudos após dez, e até, vinte anos. Outro fator de heterogeneidade da turma era a idade dos alunos, como podemos ver no gráfico da Figura 1.

Figura 1: Distribuição do número de alunos em função da idade

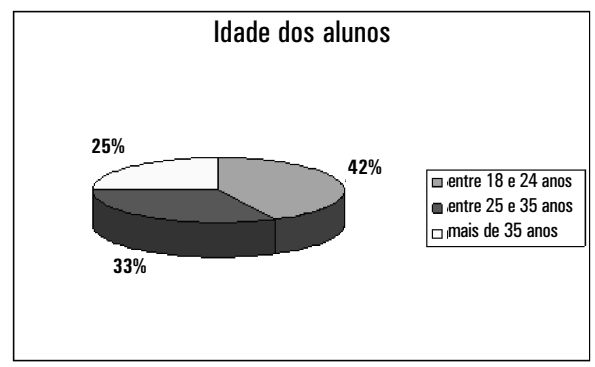

Constatamos que todos eram moradores da cidade há muitos anos e que trabalhavam, ou já tinham trabalhado, em algum setor da produção coureira. Também verificamos que apenas $20 \%$ da turma, correspondendo a 8 alunos, tinham o intuito de cursar o ensino superior, enquanto a maioria apresentava interesse em cursos técnicos, sendo a escolha predominantemente na área do calçado e na área da informática.

A partir dos dados obtidos junto aos alunos e dos fundamentos teóricos, tomamos o caminho para tornar a Física significativa e relevante para o educando, uma Física aplicada e presente no seu cotidiano, permitindo que o aluno pudesse fazer relações e analogias entre situações presenciadas no seu trabalho e os conteúdos trabalhados nas aulas. Nesse sentido, procuramos vincular o conteúdo programático com as experiências anteriores dos educandos, ao encontro do trabalho de Carvalho Júnior (2002) que apregoa a necessidade de trabalharse o conteúdo de acordo com o contexto no qual o aluno está inserido.

Levando em conta os conhecimentos profissionais do setor coureiro dos alunos da turma com quem realizamos a proposta, o tema gerador convergiu para o processo de produção do couro. Dentre as atividades propostas, à luz dos referenciais teóricos, aplicamos inicialmente um teste, cujo conteúdo pretendia avaliar os conhecimentos prévios dos educandos sobre conceitos básicos de mecânica e de operações matemáticas.

Para fazer a "ponte" entre os conhecimentos prévios manifestados pelos alunos e as novas informações que seriam abordadas em aula, promovemos também uma saída de campo com os educandos a um curtume ${ }^{1}$. Antes 
disso, elaboramos um texto sobre as etapas da produção do couro que foi trabalhado em aula. Classificamos esse texto como um dos organizadores prévios previsto por Ausubel, pois, como já mencionamos anteriormente, estes materiais introdutórios, propostos antes da utilização do material de aprendizagem, servem de ponte entre o conhecimento prévio e o material que pretendemos que seja potencialmente significativo. Então, a partir do conhecimento de todas as etapas da produção do couro, apresentamos aos alunos uma proposta dos conteúdos de mecânica que seriam abordados durante o projeto; os tópicos seriam, especificamente, a cinemática e a dinâmica do movimento circular uniforme, aplicadas ao processo de produção do couro. Optamos em trabalhar este tema em virtude de, em todas as etapas da produção coureira o movimento circular estar presente.

A aplicação do projeto teve duração de 4 (quatro) meses, com encontros semanais de duas horas-aula, totalizando trinta horas.

Os conceitos-chave abordados durante a aplicação do projeto foram: período, frequência, velocidade linear, velocidade angular, aceleração centrípeta, as forças no movimento circular, a força resultante tangencial (componente da resultante das forças na direção paralela à velocidade linear) e a força resultante centrípeta (componente da resultante das forças na direção radial). A partir do planejamento realizado, os tópicos de mecânica, sempre relacionados ao processo de produção do couro, foram abordados ao longo de aulas expositivas, incluindo atividades em grupos e individuais, apresentações de trabalhos, resolução de exercícios, elaboração de mapas conceituais e utilização de uma simulação computacional sobre o movimento circular uniforme.

O material didático utilizado nesse período foi variado. Devido a muitos alunos trabalharem em diferentes etapas da produção do couro, organizamos um pequeno texto - já citado - contendo todas as etapas do processo industrial, desde a chegada da pele ao estabelecimento até o acabamento. A utilização deste texto serviu para dar uma visão geral do processo a todos os alunos. Foram disponibilizados aos alunos textos sobre o movimento circular uniforme e as forças exercidas sobre a pele durante o processo de produção do couro. Também foram elaborados roteiros para as atividades práticas e para as que foram realizadas no laboratório de informática.

Como cada aluno trabalha em um setor da indústria de beneficiamento de couro realizamos uma saída de campo a um curtume para que todos pudessem ter uma visão mais ampla de todo o processo de produção do couro, desde a chegada da pele à indústria até o seu acabamento.

Durante a visita, em cada local que passamos, o aluno que trabalha no setor explicou ao grupo em que consistia seu trabalho e os produtos químicos que eram colocados no interior do fulão ${ }^{2}$ na etapa, bem como a frequência de rotação do fulão na mesma etapa. Neste momento da atividade colocamo-nos na condição de aprendizes, no qual percebemos, mais uma vez, para o que Paulo Freire chama a atenção, de que o conhecimento é relativo, e que todo espaço 
onde reunirem-se pessoas será um espaço de aprendizagem. Julgamos este momento como sendo um dos mais importantes do projeto, percebemos o interesse dos alunos em demonstrar ao professor o conhecimento que eles tinham sobre a produção do couro, pois sentiram-se importantes e valorizados perante o professor e o grupo.

A informática foi utilizada como recurso didático com apresentações de trabalhos em PowerPoint, bem como em uma atividade em duplas, utilizando uma simulação computacional desenvolvida no programa Modellus.

Ao final da aplicação do projeto, solicitamos aos alunos que respondessem a um teste individual abordando conceitos de mecânica, aplicados e contextualizados ao processo de produção do couro. $O$ teste inicial e o teste final foram independentes, tanto em conteúdo como em objetivos: o primeiro visava avaliar o conhecimento prévio dos aprendizes, enquanto o segundo almejava avaliar o conhecimento dos alunos referente aos conteúdos trabalhados durante a aplicação do projeto.

Os instrumentos de coletas de dados foram variados, desde relatórios sobre a saída de campo - visita a um curtume, relatórios de atividades práticas, coletas dos mapas conceituais, relatórios do uso da simulação computacional, o teste inicial e o teste final. A análise dos resultados dos testes foi quantitativa e a análise dos relatórios e mapas conceituais foi qualitativa. Os resultados obtidos serão discutidos no item 4 deste artigo.

\subsection{Utilização de mapas conceituais como instrumentos de avaliação}

Segundo Moreira (2006), mapas conceituais são diagramas que expressam relações entre conceitos por meio de uma hierarquia na distribuição destes conceitos. Podem ser utilizados como instrumentos de avaliação da aprendizagem, pois, por meio dos conceitos e da organização da estrutura dos mesmos o professor terá condições de identificar, com uma boa aproximação, como o conteúdo está organizado na estrutura cognitiva do aluno. Nesse sentido, ao término da unidade sobre a cinemática e a dinâmica no movimento circular uniforme, solicitamos aos alunos que, em grupos, construíssem mapas conceituais do conteúdo trabalhado. Os mapas foram primeiramente construídos no papel e apresentados pelos autores de cada grupo para toda a turma. Após a apresentação e discussão de cada mapa, os grupos construíram uma versão final do seu mapa. Não existe “o mapa conceitual” sobre o movimento circular uniforme, mas "um mapa conceitual" de tal movimento (MOREIRA, 2006), então, cada grupo construiu o mapa conceitual que representava a sua estrutura organizacional e hierárquica. A Figura 2 apresenta o mapa conceitual construído por um dos grupos. 
Figura 2: Mapa conceitual sobre o MCU construído por um grupo de alunos da EJA

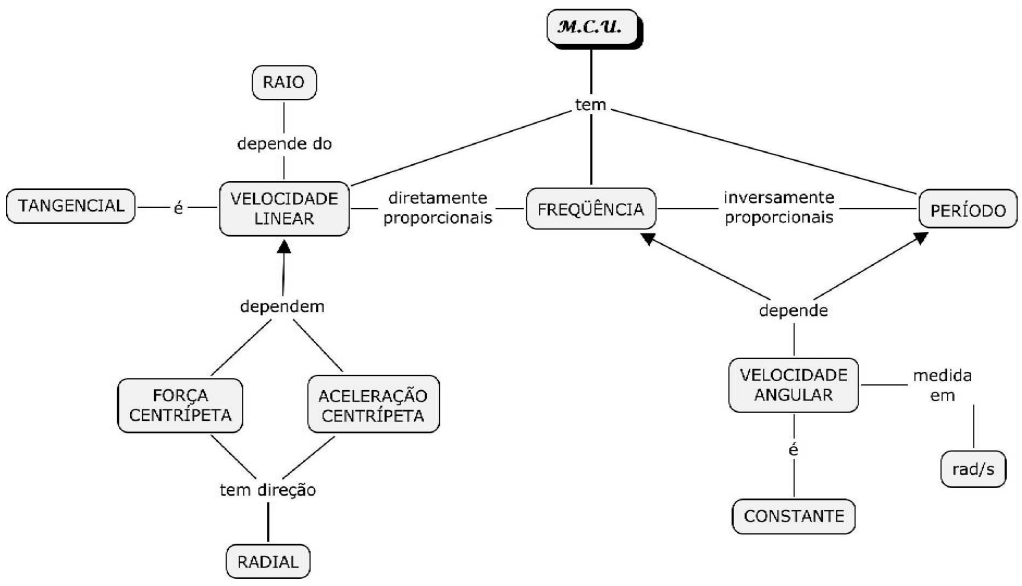

\section{Resultados Obtidos}

Para exemplificar um tipo de resultado, em uma das questões do teste final (questão 7) perguntamos em quais situações cotidianas o aluno conseguia identificar onde a Física está presente. As respostas foram bem variadas, mas todos os alunos citaram a presença da Física no trabalho, citando exemplos de movimentos circulares não apenas do fulão, como de rodas de automóveis e bicicletas. Reproduzimos a seguir algumas das respostas dos alunos para esta questão:

"A Física está presente em muitas situações do meu dia-a-dia. Na luz solar, no som que escuto, nos carros que andam e até na bicicleta que vou para o trabalho. As rodas das bicicletas e dos carros fazem um movimento circular, só que não é uniforme, pois a velocidade deles varia muito."

"Acho que a Física está presente em tudo. Antes de ter estas aulas eu achava que a Física era parecida com a Matemática, mas vi que fazemos bastante cálculos mas não só isso. No curtume onde trabalho tem Física em tudo, consegui aprender o que é periodo e frequência de um fulão e outras coisas sobre o movimento circular." (M.L.S.O.)

"Estudamos muito os movimentos circulares e como eles estão presentes no nosso dia-a-dia. Por exemplo, em um fulão, rodas de automóveis, planetas que giram, um carrossel num parque de diversão, etc." (J.S.F.)

"A Física está presente em muitos exemplos, praticamente tudo. Não apenas nos movimentos circulares dos fulões, mas em outras coisas também como um ventilador que gira ou o movimento dos planetas." (L.L.Z.)

Percebemos nas respostas que os alunos conseguiram citar outros exemplos trabalhados no decorrer do ano, mas deram ênfase aos exemplos de movimentos circulares que foi o tema da proposta do projeto. O gráfico da Figura 3 mostra a frequência de ocorrência das respostas desta questão, sendo que 39 alunos responderam ao teste e um aluno deixou o teste em branco. 
Figura 3: Frequência de ocorrência de respostas da questão 7

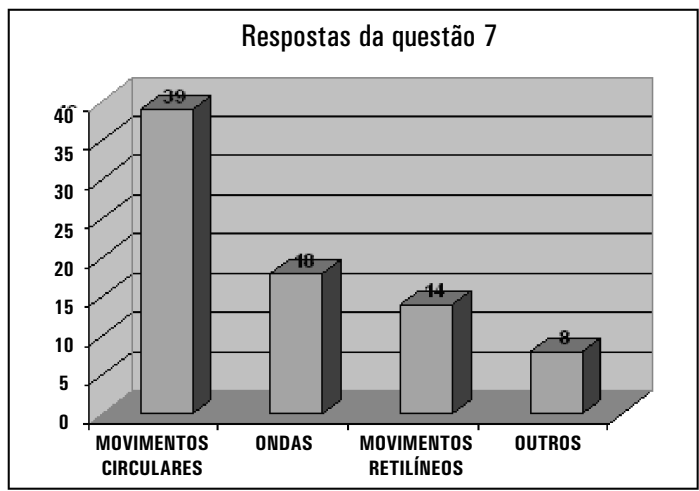

Os resultados obtidos no teste final, de maneira geral, superaram nossa expectativa. Em anos anteriores os alunos não apresentavam bom rendimento no conteúdo movimento circular. Realizamos uma análise de cada questão e percebemos que, no geral, os resultados apresentados são muito positivos. A média geral da turma no teste final foi de $87,5 \%$ de ocorrência de respostas coerentes. Desta maneira, percebemos que o material apresentado e as relações do conteúdo apresentado com situações cotidianas foram fundamentais para o bom desempenho dos alunos no projeto.

Observamos que, a maioria dos alunos (26) não pretende realizar curso superior; a justificativa apresentada foi no sentido de que uma graduação leva muitos anos para ser concluída e que eles não são mais jovens para um curso tão longo. Os alunos mais jovens pretendem ingressar em um curso superior já no ano de 2009, sendo que a área que apresentou maior frequência de respostas foi a das engenharias. Outro grupo de alunos pretende ingressar em um curso técnico, sendo as áreas preferidas da indústria de calçado, comércio e informática. Alguns alunos também escreveram que pretendem realizar algum curso de idiomas. Já um número pequeno de alunos (apenas 3) respondeu que não pretende continuar os estudos e que está contente com a conclusão do Ensino Médio.

Após trabalharmos a dinâmica do movimento circular uniforme, os alunos passaram a construir os mapas conceituais sobre o MCU. Percebemos que, na versão inicial dos mapas, os principais conceitos apareceram, porém o uso de conectores adequados não foi bem explorado. A própria falta de hábito em construir mapas conceituais foi o principal obstáculo a ser superado pelos alunos; afinal, foram os primeiros mapas construídos por eles. Todas as versões finais dos mapas apresentaram os conceitos que julgamos fundamentais sobre o tema, apresentando também, em cada mapa, alterações nos conectores e a devida utilização de setas - o que auxiliou na organização da relação entre os conceitos. Tal fato percebemos nos mapas das Figuras 4 e 5 . 
Figura 4: Versão inicial do mapa conceitual construído pelo grupo 2

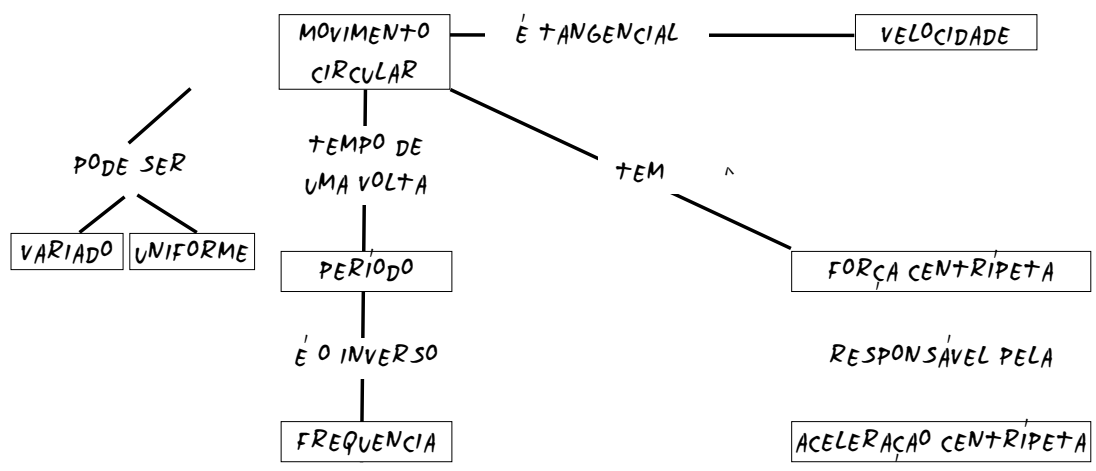

Figura 5: Versão final do mapa conceitual construído pelo grupo 2

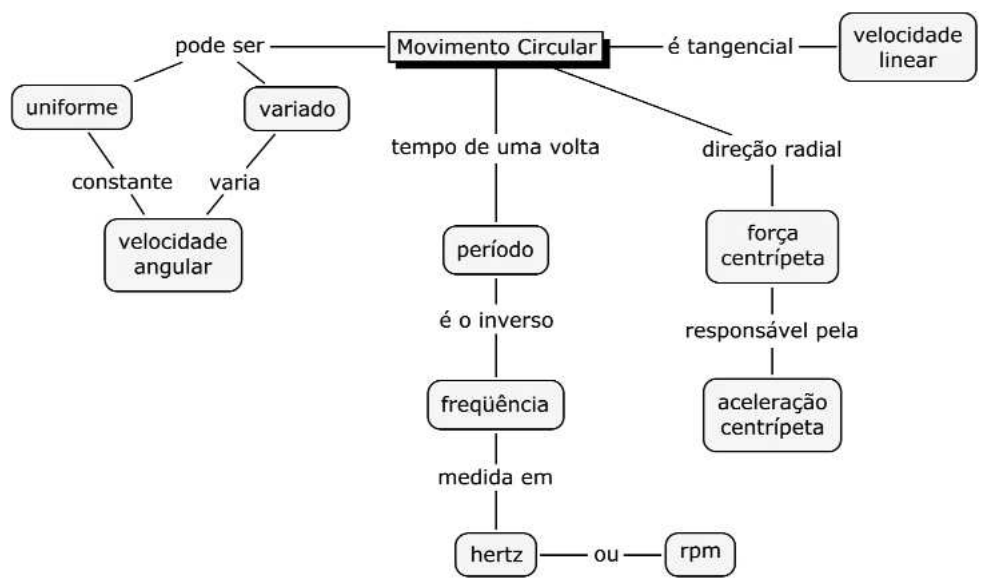

Dentre outros aspectos, um resultado extremamente significativo foi a baixa evasão. As turmas desta modalidade de ensino caracterizam-se por apresentarem elevados índices de evasão, quando a experiência docente nos permite relatar que em anos anteriores a evasão chegava a 30\%. Dos 40 alunos que iniciaram 39 concluíram o curso, resultado surpreendente, reforçando a validade da contextualização do ensino de Física como fator preponderante para este baixo índice de evasão. 


\section{Considerações Finais}

A experiência aqui relatada permite corroborar que uma metodologia que enfoque um conteúdo significativo para o educando, de maneira contextualizada, é fundamental para despertar no aluno o prazer pela ciência, dar significado e valor ao que está sendo aprendido. Elaborar uma proposta de trabalho, a partir do que o aluno já sabe, é essencial para a aprendizagem significativa. Para alcançar esse objetivo é necessário criar uma metodologia adequada e materiais didáticos que facilitem a aprendizagem significativa. Pelos resultados apresentados e analisados no item anterior, acreditamos que conseguimos desenvolver uma proposta contextualizada e motivadora. Os alunos apresentaram elevados índices de assiduidade bem como de resultados nas avaliações. Outro fato que constatamos foi a baixa evasão; em anos anteriores, muitos alunos acabavam desistindo da disciplina de Física da EJA, por não conseguirem acompanhar o conteúdo trabalhado. Tivemos apenas um aluno que desistiu do curso, o que nos leva a crer que a proposta contextualizada com o processo de produção do couro foi fundamental para tal resultado.

Durante as aulas, observamos interesse no que estava sendo trabalhado, pois percebiam que a Física estava bem mais perto do seu cotidiano do que eles imaginavam. Os alunos, constantemente, participavam da aula contribuindo com relatos de experiências profissionais sobre o tema que estava sendo proposto. De nossa parte, muitas aprendizagens foram feitas com a contribuição dos alunos: enquanto a Física era discutida, aplicada à produção do couro, eles nos ensinavam a parte técnica necessária para a produção. Desta forma pudemos vivenciar a justeza do pensamento de Paulo Freire (2003) quanto aos saberes relativos do professor e dos alunos.

Acreditamos que propostas de ensino contextualizado podem valer não apenas para a disciplina de Física, podendo ser elaborados, interdisciplinarmente, um mesmo tema em comum. Desenvolvemos uma proposta a partir de experiências profissionais dos alunos, cujo tema gerador também poderia ser utilizado para trabalhar a Química, já que esta ciência está presente em todas as etapas da produção do couro. A Biologia poderia trabalhar o tema do reaproveitamento da água utilizada pelos curtumes, bem como o tema do impacto ambiental causado pelas indústrias coureiras no solo. A História poderia trabalhar temas referentes ao histórico das indústrias desta área na região do Vale do Rio dos Sinos. Enfim, acreditamos que propostas contextualizadas podem ser efetivadas com um tema gerador específico para cada realidade local, favorecendo assim, o interesse e a motivação para o estudo e facilitando a ocorrência da aprendizagem significativa. 


\section{NOTAS}

1 Indústria de beneficiamento e produção de peles e couros.

2 O fulão é um recipiente, normalmente cilíndrico, com eixo de simetria posicionado na horizontal, girando em torno desse eixo graças a um motor que o aciona por meio de um sistema de polias acopladas por correias. Seu objetivo é transformar a pele animal em couro pela ação mecânica.

\section{REFERÊNCIAS BIBLIOGRÁFICAS}

AUSUBEL, D. P. Psicología educativa: un punto de vista cognoscitivo. México: Trillas, 1976. 769p.

AUSUBEL, D. P.; NOVAK, J. D.; HANESIAN, H. Psicología Educacional. Rio de Janeiro: Interamericana, 1980. 626p.

BRASIL. Ministério da Educação: Secretaria de Educação Média e Tecnológica. Parâmetros Curriculares Nacionais: Ensino Médio. Brasília: Ministério da Educação, 1999. 364p.

CARVALHO Jr., G. D. As concepções de ensino de Física e a construção da cidadania. Caderno Brasileiro de Ensino de Física, Florianópolis, v. 19, n. 1, p. 53-66, abr. 2002.

ESPÍNDOLA, K. A estratégia dos projetos didáticos no ensino de Física na educação de jovens e adultos (EJA), Porto Alegre: UFRGS, Instituto de Física, Programa de Pós-Graduação em Ensino de Física. Dissertação de mestrado. 2006.

FREIRE, P. Pedagogia do oprimido. $29^{a}$ ed. Rio de Janeiro: Paz e Terra, 2000. 218p.

FREIRE, P. Pedagogia da autonomia: saberes necessários à prática educativa. $19^{\mathrm{a}}$ ed. Rio de Janeiro: Paz e Terra, 2001. 165p.

FREIRE, P. Educação e mudança. $27^{\mathrm{a}}$ ed. Rio de Janeiro: Paz e Terra, 2003. 79p.

GNEIDING, I. M.; GARCIA, N. M. D. O que justifica um assunto de Física ser lembrado por um trabalhador? In: XVII Simpósio Nacional de Ensino de Física. São Luis, Maranhão, de 29 de janeiro a 02 de fevereiro de 2007. ATAS. Disponível em: <http://www.sbf1.sbfisica.org.br/eventos/snef/xvii/atas/>. Acesso em 05 de fevereiro de 2009.

KRUMMENAUER, W. L. O movimento circular uniforme para alunos da EJA que trabalham no processo de produção do couro. Porto Alegre: UFRGS, Instituto de Física, Programa de Pós-Graduação em Ensino de Física. Dissertação de mestrado. 2009.

LOZADA, C. O.; LOZADA, A. O.; ROZAL, E. F. Utilização de textos em aulas de Física na Educação de Jovens e Adultos. In: XI Encontro de Pesquisa em Ensino de Física. Anais. Curitiba, 21 a 24 de outubro de 2008. Trabalho apresentado no XI EPEF, Curitiba: UTFPR, 2008. 96p.

MOREIRA, M. A.; OSTERMANN, F. Teorias construtivistas. Porto Alegre: Gráfica do Instituto de Física - UFRGS, 1999. 63p.

MOREIRA, M. A. Mapas conceituais e diagramas V. Porto Alegre: Ed. do autor, 2006. 103p.

MOREIRA, M. A.; MASINI, E. F. S. Aprendizagem significativa: a teoria de David Ausubel. $2^{\mathrm{a}}$ ed. São Paulo, SP: Moraes, 2006. 112p.

SILVA, A. V. Uma reflexão para a prática educativa em Paulo Freire. Revista Espaço Acadêmico, Ilhéus, №. 45, Fev. 2005. Disponível em:

<http://www.espacoacademico.com.br/045/45pc_silva.htm>. Acesso em: 10 jan. 2008.

SOARES, L. Educação de Jovens e Adultos. $1^{\mathrm{a}}$ ed. Rio de Janeiro: DP\&A Editora, 2002. 168p.

VALADARES, J. Como facilitar a aprendizagem significativa e rigorosa da Física. In: XVI Simpósio Nacional de Ensino de Física. Anais. Rio de Janeiro, 24 a 28 de janeiro de 2005. Disponível em: <http://www.sbf1.sbfisica.org.br/eventos/snef/xvi/> Acesso em: 5 de fevereiro de 2009. 
